\title{
Management, Procurement and Law: Referees 2019
}

The following is a list of referees who have reviewed papers for Management, Procurement and Law between 1 January 2019 and 31 December 2019. The Institution of Civil Engineers is very grateful for their assistance.

We are continually looking for suitable reviewers for papers submitted to Management, Procurement and Law. Papers published in the Proceedings of the ICE must be submitted to at least two independent referees to judge accuracy, style, impact, importance and interest.

If you are interested in reviewing articles on any topic related to management, procurement and law, please submit your name, qualifications or $\mathrm{CV}$, and

Emmanuel Aboagye-Nimo

Andrew Agapiou

Aibinu Ajibade

Bankole Awuzie

Francine Baker

Jon Broome

Paul Chan

Jennifer Charlson

William Collinge

Shang Gao

Robert Gerrard

Joel Gilmour

Christian Henjewele
Nick Higgs

Al Jarratt

Ruoyu Jin

Kaushal Keraminiyage

Kenneth Lawani

Finbarr Leach

Hongyang Li

Wayne Lord

Colm Lundrigan

Jim Mason

Ian Massey

Philip McAleenan

Ciaran McAleenan areas of expertise. We are in need of individuals who will agree to review papers in a timely fashion (within 3 to 4 weeks of receipt) and provide confidential feedback to the Editorial Advisory Panel concerning the quality of the paper and any suggested revisions that would be appropriate.

If you are such a person, please contact Rebecca Rivers (tel.: +44 (0)207 665 2241; e-mail: rebecca.rivers@ice.org.uk) for more information on the referee process.
Rajeev Ruparathna

Saad Sarhan

Libby Schweber

Lloyd Scott

Fred Sherratt

Wakisa Simukonda

John Spillane

Alfred Staerk

Y. W. Daniel Tay

Derek Thomson

Michelle Turner

Terence Vaughan 